\title{
Mechanical Properties and Service Life Prediction of Modified Concrete Attacked by Sulfate Corrosion
}

\author{
Min Zhang, ${ }^{1}$ Li-min Yang, ${ }^{2}$ Jin-Jun Guo $\mathbb{D}^{1},{ }^{1}$ Wen-li Liu, ${ }^{1}$ and Hong-li Chen ${ }^{1}$ \\ ${ }^{1}$ School of Water Conservancy and Environment, Zhengzhou University, Zhengzhou 450001, China \\ ${ }^{2}$ China Construction Seventh Engineering Division Corp. Ltd., Zhengzhou 450004, China \\ Correspondence should be addressed to Jin-Jun Guo; guojinjun@zzu.edu.cn
}

Received 31 August 2017; Accepted 17 December 2017; Published 13 February 2018

Academic Editor: Song Han

Copyright (c) 2018 Min Zhang et al. This is an open access article distributed under the Creative Commons Attribution License, which permits unrestricted use, distribution, and reproduction in any medium, provided the original work is properly cited.

Under the condition of drying and wetting circulation, ordinary concrete, modified concrete containing fly ash, and doubleadmixture concrete containing fly ash and polypropylene fiber were corroded in the solution of $\mathrm{Na}_{2} \mathrm{SO}_{4}$ and $\left(\mathrm{NH}_{4}\right)_{2} \mathrm{SO}_{4}$. The sulfate concentration of the solution was designed to be $1000 \mathrm{~g} / \mathrm{L}$. The compressive strength and splitting tensile strength of the concrete were tested after different number of drying and wetting cycles $(0,2,4,6,8$, and 10). The results indicate that the strength of concrete increases in the early stages of corrosion and decreases gradually later. The admixture significantly improves the resistance to sulfate erosion of the modified concrete, while polypropylene fiber plays a less important role on anticorrosion properties. When suffered 10 times of drying and wetting cycle, the compressive strength and splitting tensile strength of modified concrete increase by $28 \%$ and $19 \%$, respectively. Based on the test results, the service life of the modified concrete corroded by sulfate was predicted.

\section{Introduction}

There are many saline soil areas containing a large amount of strong corrosive medium, such as sulfate and chloride, in Western China. For example, the sulfate concentration is more than $4200 \mathrm{mg} / \mathrm{L}$ in saline soil of Qinghai Province, which belongs to the strong corrosion level and results in severe corrosion of concrete structures [1]. There is also a great deal of large soil areas containing sulfate in Canada and the United States, in which concrete drainage pipes, concrete culverts, and foundation were damaged due to sulfate corrosion [2]. In recent years, most of the concrete structures serving long time in seawater environment, such as submarine tunnels, sea bridges, and harbors, were degraded because of sulfate corrosion in different degree, especially in areas where the water level changes as a result of the tides. The sulfate corrosion under dry-wet circulation circumstance causes severe damage to concrete structures. Therefore, the reliability of concrete structures is seriously affected by sulfate erosion.

Concrete corrosion mechanism varies greatly with different sulfate conditions [3]. The different chemical reactions are caused by differences of erosion solution concentrations, temperatures, cation types, and drying and wetting conditions. Santhanam et al. studied the effects of sulfate concentration of sodium sulfate and magnesium sulfate on swelling rate of cement mortar [4]. Ma et al. investigated the failure mechanism of concrete attacked by sulfate in marine tide environment and measured the sulfate concentration at different mix ratio and erosion age [5]. Li researched the degradation models of concrete affected by single-factor or double-factor coupling such as carbonization, sulfate erosion, and freeze-thaw cycle [6]. Yu et al. investigated the deterioration process under the effects of flexure load, dry-wet cycle, and sulfate attack and microstructure of eroded concrete, which indicated that the dry-wet cycle played the major role in concrete damage [7]. At present, due to the different research objectives and the different test environments, the different test schemes and the evaluation indexes are selected to study the performance of concrete subjected to sulfate attack [8]. Therefore, the research in this field is still in a chaotic state [9], and there is no unified accepted knowledge system. How to improve the corrosion resistance of concrete structures is of great engineering significance. 
TABLE 1: Mix proportions of concrete composites.

\begin{tabular}{lccccccc}
\hline & & \multicolumn{4}{c}{ Mix proportion $\left(\mathrm{kg} / \mathrm{m}^{3}\right)$} & & \\
Types of concrete & Water/binder & Cement & Water & Fine aggregate & Coarse aggregate & Fly ash & PP fiber \\
\hline Ordinary & 0.57 & 342.0 & 195 & 663 & 1180 & 0 & 0 \\
Fly ash & 0.52 & 273.6 & 195 & 600 & 1180 & 102.6 \\
Double-mixture & 0.52 & 273.6 & 195 & 600 & 1180 & 0 \\
\hline
\end{tabular}

The purpose of researching mechanical properties of concrete subjected to sulfate attack is to improve the anticorrosion capacity of the concrete. Therefore, it is of great importance to explore new corrosion-resistant modified concrete materials. In engineering, most of concrete structures work in service under drying and wetting conditions instead of completely dry or wet sulfate environments, which makes the concrete corroded rapidly and severely. In this study, the ordinary concrete, fly ash concrete, and double-mixture concrete (including fly ash and polypropylene) corroded by $\mathrm{Na}_{2} \mathrm{SO}_{4}$ and $\left(\mathrm{NH}_{4}\right)_{2} \mathrm{SO}_{4}$ were tested in drying and wetting conditions with $1000 \mathrm{~g} / \mathrm{L} \mathrm{SO}_{4}^{2-}$ in solution. Mechanical properties of modified concrete suffered from sulfate corrosion were researched, and the variation trend of the compressive strength of fly ash concrete was analyzed. Based on the test results, the service life of the modified concrete was predicted.

\section{Experimental Program}

2.1. Raw Materials and Mix Proportions. A Chinese standard (GB175-2007) [10] Portland cement Class 32.5R (which has standard compressive strength of $32.5 \mathrm{MPa}$ at the age of 28 days) was used. A Chinese standard (GB/T1596-2005) [11] Grade I fly ash was used as admixture to make the concrete. A Chinese standard (GB/T21120-2007) [12] polypropylene fiber was used to make the concrete, the length of which was $19 \mathrm{~mm}$. Coarse aggregate with a maximum size of $20 \mathrm{~mm}$ and fine aggregate with a 2.76 fineness modulus were used. The bulk density and apparent particle density of coarse aggregates were $1450 \mathrm{~kg} / \mathrm{m}^{3}$ and $2720 \mathrm{~kg} / \mathrm{m}^{3}$, respectively. The slump of concrete was $35 \sim 50 \mathrm{~mm}$. The designed strength grade of concrete was C25. Three types of concrete specimens were cast, including ordinary concrete, fly ash concrete, and double-admixture concrete (containing fly ash and polypropylene). A Chinese standard (JGJ 55-2011) [13] and the mix proportions used in this study are presented in Table 1.

2.2. Experiment Method. A series of cubic concrete specimens with the size of $100 \mathrm{~mm} \times 100 \mathrm{~mm} \times 100 \mathrm{~mm}$ were cast including ordinary concrete, fly ash concrete, and doublemixture concrete. Two solutions of $\mathrm{Na}_{2} \mathrm{SO}_{4}$ and $\left(\mathrm{NH}_{4}\right)_{2} \mathrm{SO}_{4}$ were compounded in the experiment, and the sulfate concentration was designed to be $1000 \mathrm{~g} / \mathrm{L}$. Under the condition of each corrosion solution, 12 groups of specimens were casted for each type of concrete, which include 6 groups for compressive strength test and 6 groups for splitting tensile strength test. The total numbers of specimens was 288 . The specimens were cured for 28 days at ambient temperature

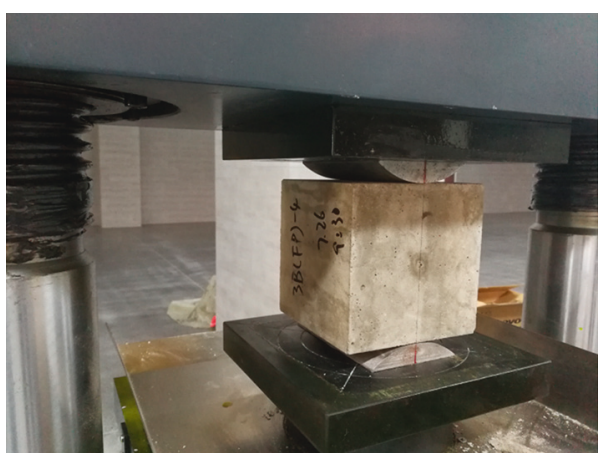

FiguRE 1: Splitting tensile strength experiment of concrete.

with straw mats and watered twice a day to ensure the moisture of specimens. The size of the solution box is $1000 \mathrm{~mm}(\mathrm{l}) \times 600 \mathrm{~mm}(\mathrm{w}) \times 600 \mathrm{~mm}(\mathrm{~h})$.

During the course of the experiment, the concentration of $\mathrm{SO}_{4}^{2-}$ in the solution was monitored on time to maintain the concentration unchanged basically. The corrosion solution was reconfigured to replace the original solution when the color of solution was changed or the content of other impurities was excessive. The bottom of the corrosion box was dredged in time so that the corrosion precipitations were not too thick.

The concrete specimens cured for $28 \mathrm{~d}$ were immersed in the solutions of $\mathrm{Na}_{2} \mathrm{SO}_{4}$ and $\left(\mathrm{NH}_{4}\right)_{2} \mathrm{SO}_{4}$, respectively, and separated by some wooden bars each other. The drying and wetting cycle system was designed as one week for immersing in solution and one week for air drying. Two weeks was one drying and wetting cycle. The cubic compressive strength $f_{\text {cu }}$ and splitting tensile strength $f_{\text {st }}$ of three types of concrete specimens were tested after $0,2,4,6,8$, and 10 cycles, respectively. The strength tests were performed in accordance with Chinese standard (SL 352-2006) [14].

The electrohydraulic pressure testing machine (Type YA-3000; SCHIAK Company, Shanghai, China) was used in the experiment of compressive strength of concrete cubes. According to the Chinese standard (SL 352-2006), loading should be loaded uniformly and continuously at the speed of $0.3 \mathrm{MPa} / \mathrm{S}$ to $0.5 \mathrm{MPa} / \mathrm{S}$. The universal testing machine (Type WE-X00; SCHIAK Company) was used in the experiment of splitting tensile strength of concrete cubes. Loading speed was $0.04 \mathrm{MPa} / \mathrm{S}$ to $0.06 \mathrm{MPa} / \mathrm{S}$. The picture of splitting tensile experiment is shown in Figure 1.

\section{Experiment Results and Discussion}

3.1. Mechanical Properties of Ordinary Concrete and Modified Concrete in Different Solutions. Due to different cations, the 


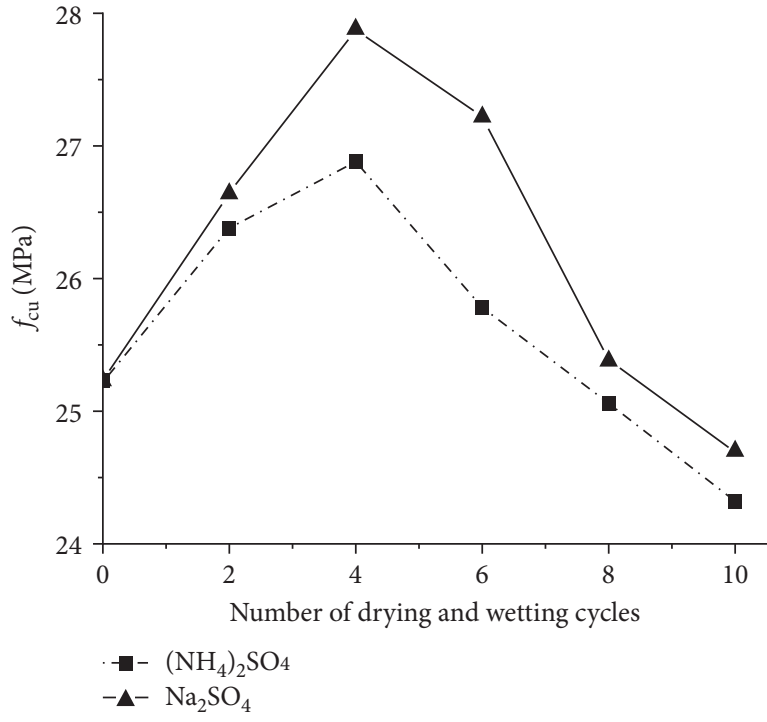

(a)

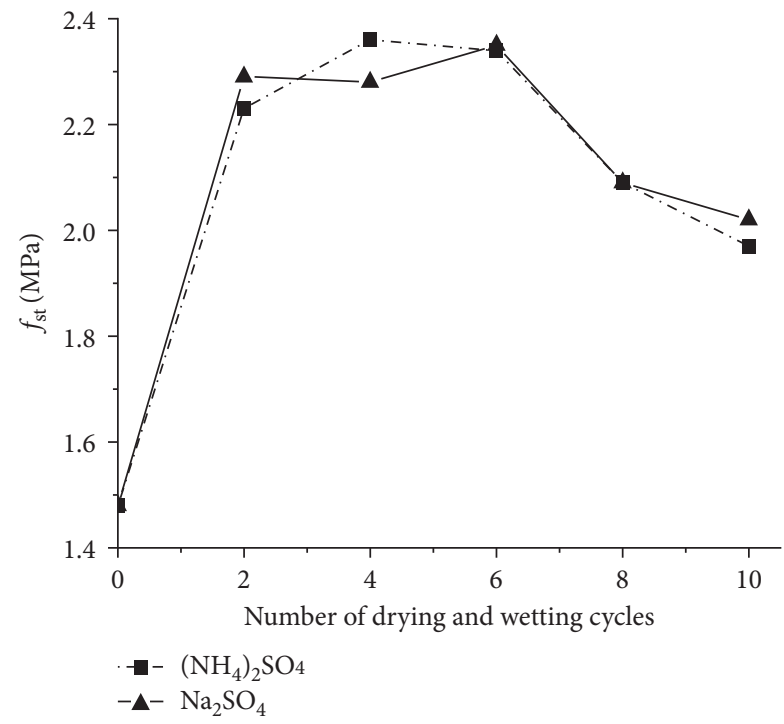

(b)

FIGURE 2: Changes in the strengths of corroded ordinary concrete varied to dry-wet cycles. (a) Compressive strength. (b) Splitting tensile strength.

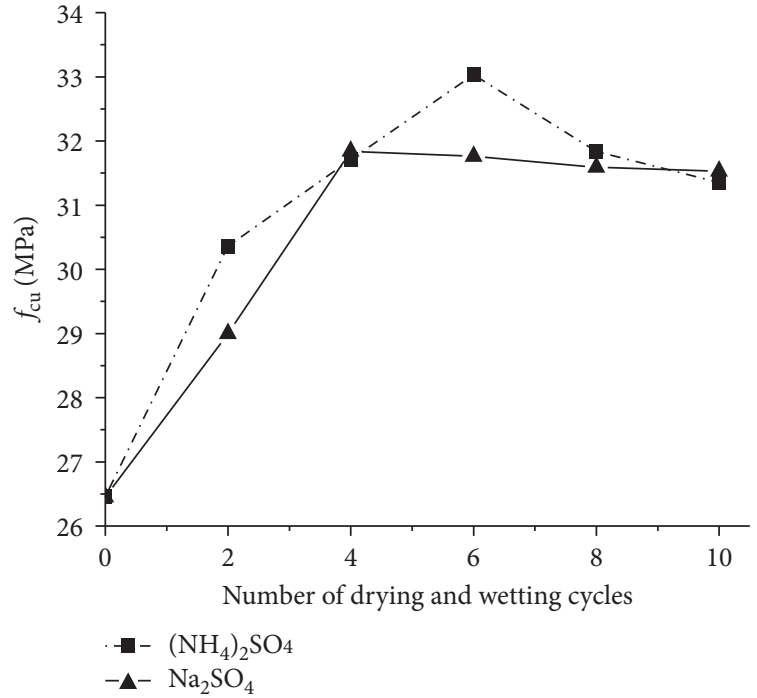

(a)

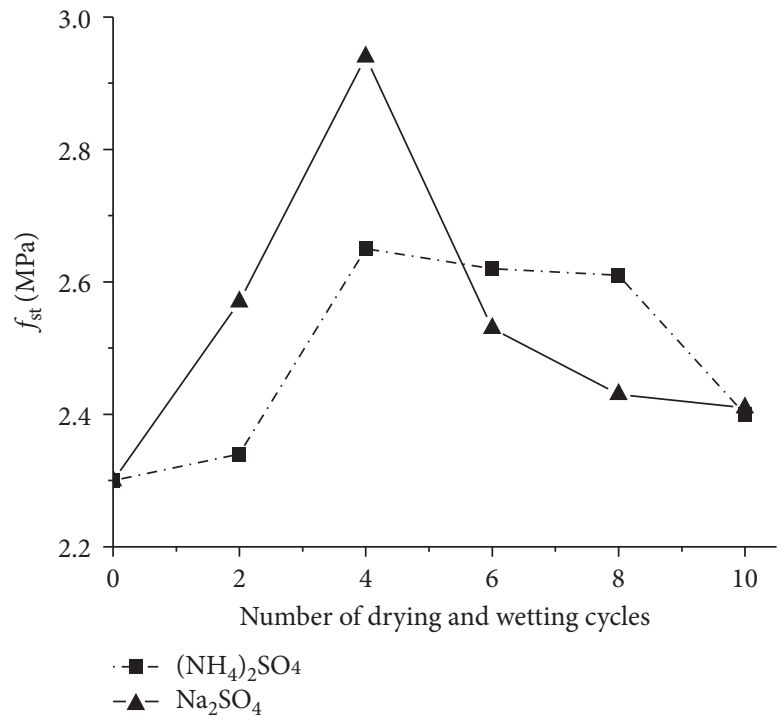

(b)

FIgure 3: Changes in the strengths of corroded fly ash concrete varied to dry-wet cycles. (a) Compressive strength. (b) Splitting tensile strength.

degrees of concrete corrosion in sulfate solutions are various. The compressive strength and splitting tensile strength of ordinary concrete and modified concrete corroded by $\mathrm{Na}_{2} \mathrm{SO}_{4}$ and $\left(\mathrm{NH}_{4}\right)_{2} \mathrm{SO}_{4}$ varied to dry-wet cycles are presented in Figures $2-4$, respectively.

In Figures 2-4, the strength development of ordinary concrete and modified concrete corroded by sulfate solutions can be basically classified into two stages which are initial strengthening section and performance deterioration phase. At the beginning of corrosion, ions $\mathrm{SO}_{4}^{2-}$ react with hydration of cement to form gypsum and ettringite, which is a volume expansion process [15]. Sulfate reactants fill in the holes inside the concrete and the interfacial spaces between the aggregate and paste by means of corrosion reactions, which improve structure compactness and early strength of concrete. As the corrosion time is increasing, more and more expansive corrosion products are formed to increase the internal stress and damage the pore structure of concrete gradually. As a result, the internal microcracks extend continuously so that the strength of the concrete 


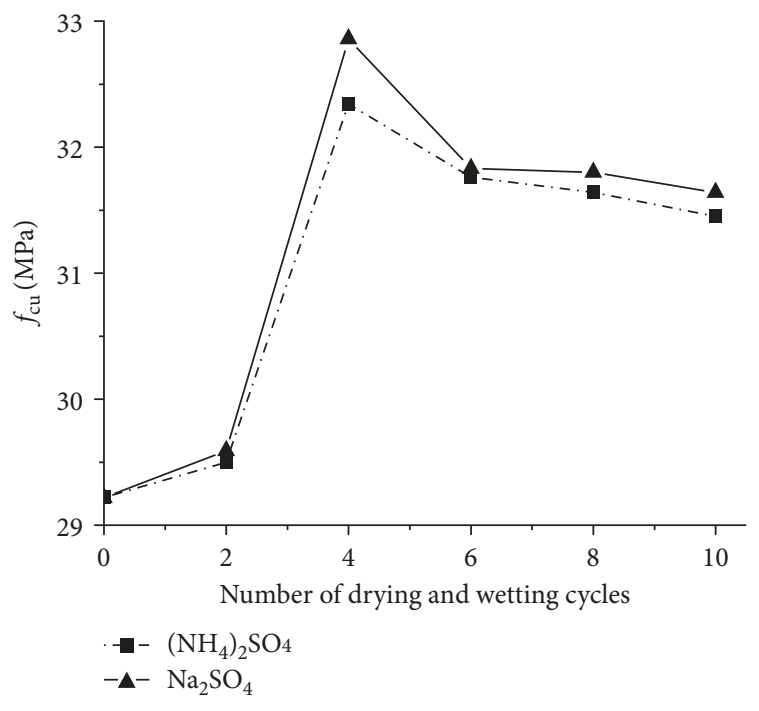

(a)

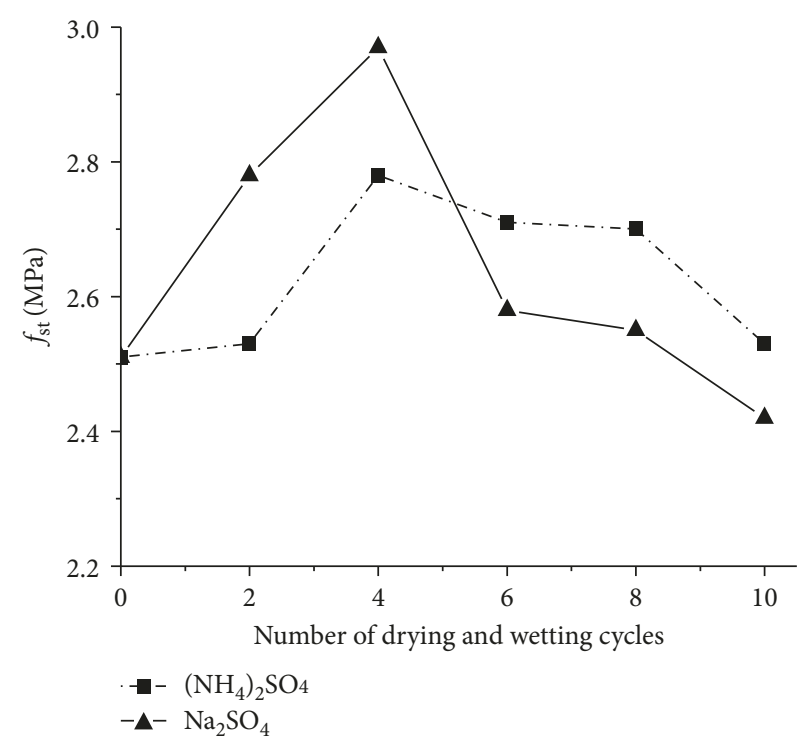

(b)

Figure 4: Changes in the strengths of corroded double-admixture concrete fly ash and polypropylene concrete varied to dry-wet cycles. (a) Compressive strength. (b) Splitting tensile strength.

drops gradually in the later stage [16]. From the figures, the splitting tensile strength of concrete decreases faster than compressive strength in the later stage with the increasing of dry-wet cycle number. With the accumulation of microcracks caused by corrosion and the partial exfoliation of surface concrete, the stressed area of the specimen in the splitting test is decreased, and microcrack expansion is accelerated resulting in the sharper declined rate. However, in the compressive strength test, the upper and lower pressure plates restrict the development of microcracks in the surface layer of concrete to some degree, and the downward trend of the compressive strength is slower.

The experimental results show that two different corrosion solutions make little difference on the compressive strength of modified concrete undergoing the same drying and wetting cycles. However, the splitting tensile strength varies to the different solution. At the initial strengthening stage, the splitting tensile strength of modified concrete corroded by sodium sulfate is generally higher than that in ammonium sulfate solution. The splitting tensile strengths of fly ash concrete and double-admixture concrete in sodium sulfate solution increase $10.9 \%$ and $6.8 \%$, respectively, compared with those in the ammonium sulfate solution after four dry-wet cycles. At performance deterioration stage, the splitting tensile strength of the modified concrete decreased more rapidly in $\mathrm{Na}_{2} \mathrm{SO}_{4}$ to be lower than that in $\left(\mathrm{NH}_{4}\right)_{2} \mathrm{SO}_{4}$. For example, the splitting tensile strengths of fly ash concrete and double-mixture concrete in $\mathrm{Na}_{2} \mathrm{SO}_{4}$ are $93 \%$ and $94 \%$ of that in $\left(\mathrm{NH}_{4}\right)_{2} \mathrm{SO}_{4}$, respectively, after 8 dry-wet cycles.

At the beginning of corrosion, the interaction between $\mathrm{NH}_{4}^{+}$and $\mathrm{Ca}(\mathrm{OH})_{2}$ neutralizes the hardened cement paste, which results in weakening of bond force of the cement gel and aggravation of $\mathrm{SO}_{4}^{2-}$ corrosion [17]. At the deterioration stage, due to the effects of drying and wetting cycle, $\mathrm{Na}_{2} \mathrm{SO}_{4} \cdot 10 \mathrm{H}_{2} \mathrm{O}$ crystal will be precipitated in the internal pores of concrete when the content of $\mathrm{Na}_{2} \mathrm{SO}_{4}$ exceeds its solubility [18]. With the increase of the expansible corrosion products, such as ettringite and gypsum, the developing of the internal cracks in concrete is accelerated, and consequently the corrosive effect of sulfate is exacerbated further. So, the splitting tensile strength of concrete decreases sharply in sodium sulfate solution.

3.2. Effect of Admixtures on Corrosion Resistance Properties of Concrete. In order to intuitively describe the influence of the admixtures on properties of concrete attacked by sulfate corrosion, the relative compressive strength ratio $R_{c}$ and relative splitting tensile strength ratio $R_{t}$ are defined to characterize the variation of the strength of the modified concrete:

$$
\begin{aligned}
& R_{c}=\frac{f_{\mathrm{cu}}^{m}}{f_{\mathrm{cu}}^{0}}, \\
& R_{t}=\frac{f_{\mathrm{st}}^{m}}{f_{\mathrm{st}}^{0}},
\end{aligned}
$$

where $f_{\mathrm{cu}}^{m}$ and $f_{\mathrm{st}}^{m}$ are compressive strength and splitting tensile strength of modified concrete, respectively, undergoing the dry-wet cycles and $f_{\mathrm{cu}}^{0}$ and $f_{\mathrm{st}}^{0}$ are compressive strength and splitting tensile strength of ordinary concrete with the same dry-wet cycles, respectively. The relative compressive strength ratio $R_{c}$ and relative splitting tensile strength ratio $R_{t}$ changes of modified concrete corroded by $\mathrm{Na}_{2} \mathrm{SO}_{4}$ and $\left(\mathrm{NH}_{4}\right)_{2} \mathrm{SO}_{4}$ are presented in Figures 5-8, respectively.

Figures 5 and 6 show the variation trends of the relative compressive strength ratio and relative splitting tensile strength ratio of fly ash concrete and fly ash-polypropylene fiber concrete eroded by $\mathrm{Na}_{2} \mathrm{SO}_{4}$. Figures 7 and 8 show the variation trends of the relative compressive strength ratio and 


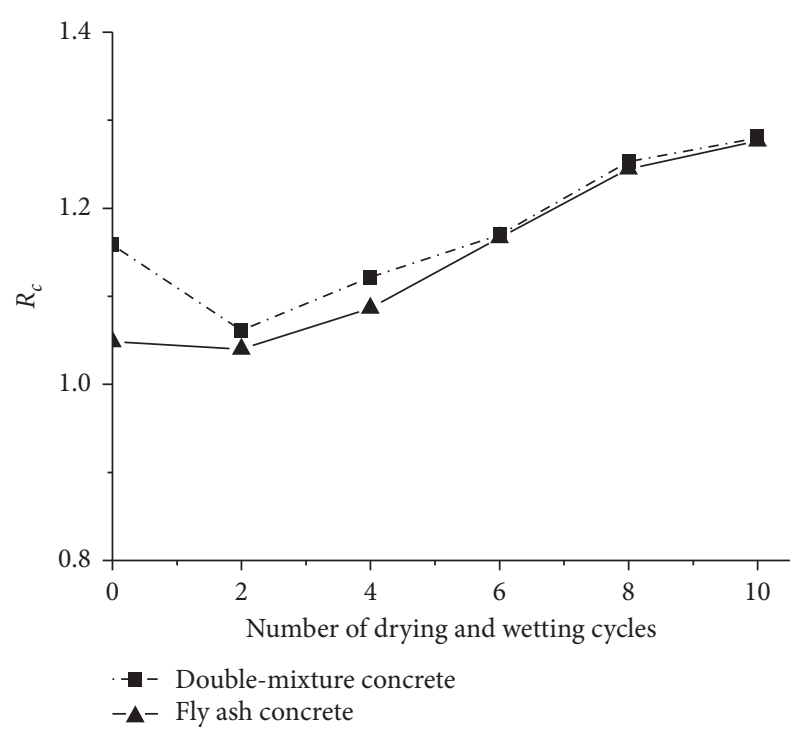

FIGURE 5: Relative compressive strength ratio of modified concrete corroded by $\mathrm{Na}_{2} \mathrm{SO}_{4}$ solution.

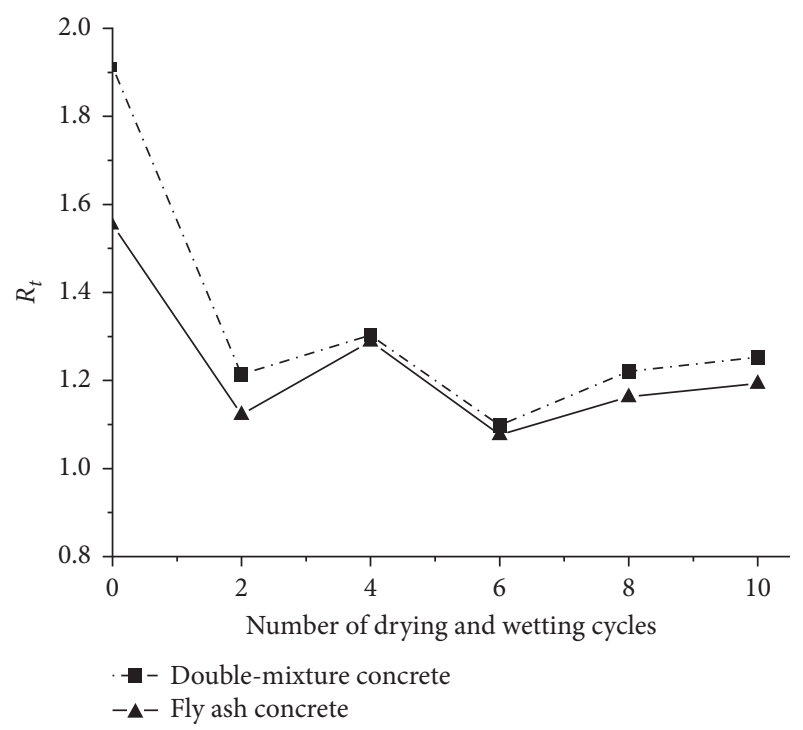

FIGURE 6: Relative splitting tensile strength ratio of modified concrete corroded by $\mathrm{Na}_{2} \mathrm{SO}_{4}$ solution.

relative splitting tensile strength ratio of fly ash concrete and fly ash-polypropylene fiber concrete eroded by $\left(\mathrm{NH}_{4}\right)_{2} \mathrm{SO}_{4}$.

It is clear that the relative strength ratio curve of modified concrete always exceeds 1.00 , which indicates that the addition of admixture improves the ability of sulfate resistance of concrete. Physically speaking, the addition of fly ash reduces the porosity ratio of the concrete and improves the porosity characteristic by replacing a large quantity of cement and fine aggregate, so the impermeability of concrete is increased [19]. Chemically, fly ash reacts with calcium hydroxide to form some gel, which blocks the porous channels and makes the porous structure thinned and concrete structure compacted, to decrease the flow speed of $\mathrm{SO}_{4}^{2-}$ in pores. In addition, the

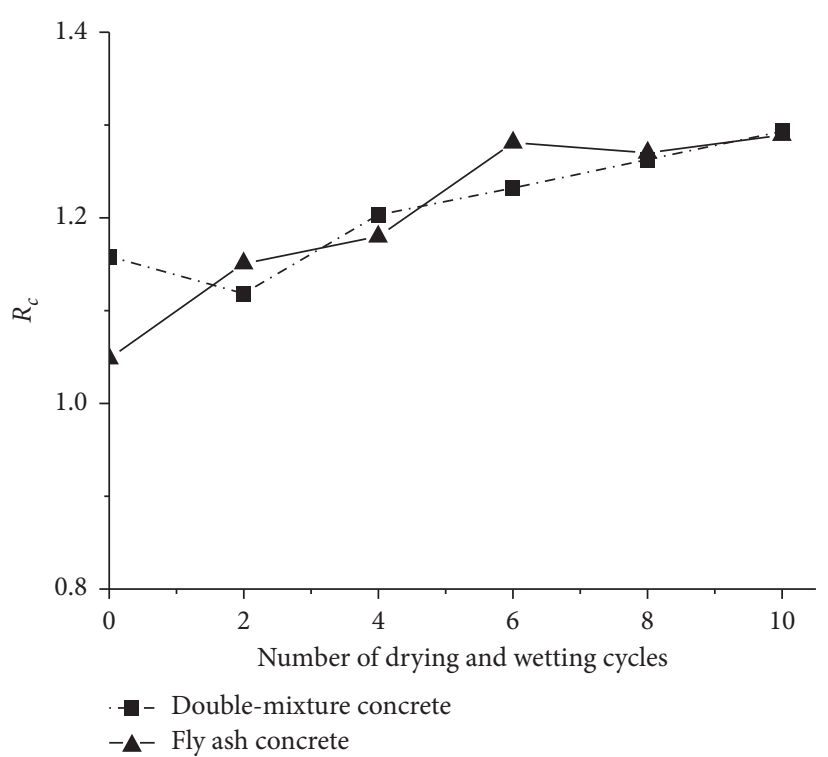

FIGURE 7: Relative compressive strength ratio of modified concrete corroded by $\left(\mathrm{NH}_{4}\right)_{2} \mathrm{SO}_{4}$ solution.

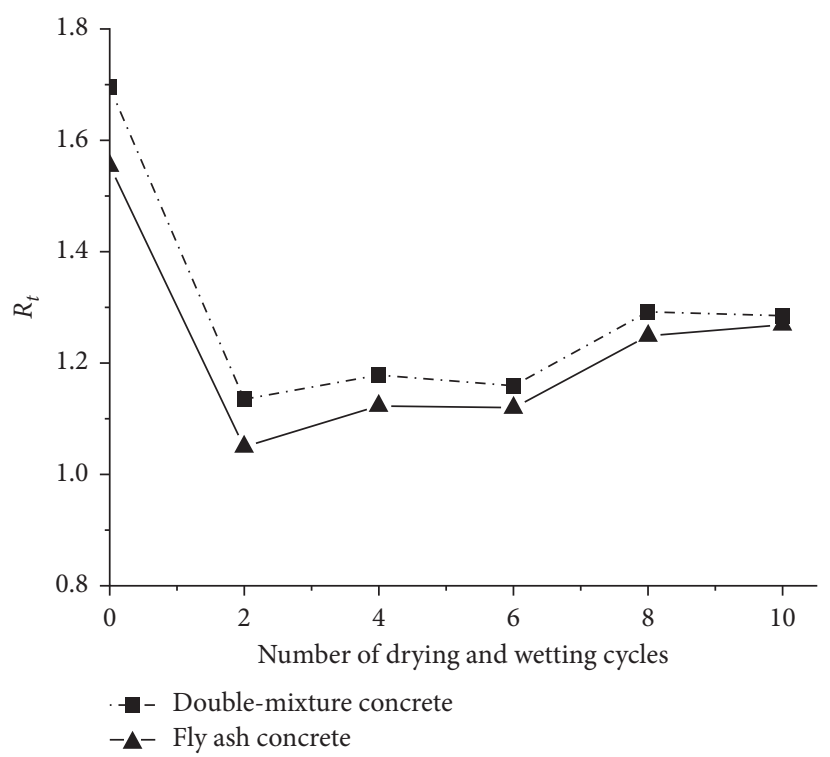

FIGURE 8: Relative splitting tensile strength ratio of modified concrete corroded by $\left(\mathrm{NH}_{4}\right)_{2} \mathrm{SO}_{4}$ solution.

active effect of fly ash can consume calcium hydroxide, which reduces the amount of calcium hydroxide reacted with sulfate, to slow down the process of sulfate attack and reduce the degree of erosion. Addition of polypropylene fibers effectively controls the development of microcracks of concrete caused by solid plastic shrinkage, drying shrinkage, and temperature change. The performances of seepage proofing and crack resistance of concrete are improved [20].

As can be seen from $R_{c}$ curve, the relative compressive strength ratio of the modified concrete roughly presents growth trend. Due to the faster growth of concrete strength 
mixed with fly ash, the growth rate of compressive strength of the modified concrete is higher than that of the ordinary concrete in the early stage of corrosion. At the deterioration stage, the strength of the ordinary concrete drops faster. The value of $R_{c}$ reaches its maximum after 10 dry-wet cycles. The compressive strengths of fly ash concrete and double-mixture concrete increase $27.7 \%$ and $28 \%$ than those of ordinary concrete in $\mathrm{Na}_{2} \mathrm{SO}_{4}$, respectively, and increase $28.9 \%$ and $29.3 \%$ than those in $\left(\mathrm{NH}_{4}\right)_{2} \mathrm{SO}_{4}$. The results show that the admixture materials significantly improve the ability of concrete against sulfate corrosion.

As can be seen from $R_{t}$ curve, the relative splitting tensile strength ratio of fly ash concrete and double-mixture concrete has the maximum value of 1.554 and 1.700 , respectively, at the beginning of corrosion. The trends of $R_{t}$ of modified concrete decline at first and then increase later in the two solutions. Compared with the modified concrete, the splitting tensile strength of the ordinary concrete grows faster in the early stage of corrosion and decreases faster in the later stage.

Comparing $R_{c}$ and $R_{t}$ curves of the modified concrete, the strength of double-mixture concrete is higher than that of fly ash concrete at initial corrosion period. The compressive strength and splitting tensile strength of doublemixture concrete are 1.105 times and 1.091 times as that of fly ash concrete, respectively. However, the strength ratio curves of two kinds of modified concretes are almost coincided after the second cycle. According to the test data, the strength difference between the two kinds of concrete is not more than $10 \%$. Therefore, polypropylene fiber plays a role in improving the performance of seepage and crack resistance of concrete but has little effect on increasing the ability of concrete against sulfate corrosion compared with fly ash concrete. Considering the economic efficiency and resource conservation, it is suggested not to add polypropylene fiber into fly ash concrete.

\section{Life Prediction of Concrete Corroded by Sulfate}

As mentioned above, fly ash concrete is used as an example to predict the failure time of concrete corroded by sulfate solution. The relative compressive strength is adopted as an index to evaluate the damage process of concrete under sulfate attack.

$$
K_{c}=\frac{f_{\mathrm{cn}}}{f_{c 0}} \times 100 \%,
$$

where $K_{c}$ is the relative compressive strength of concrete specimen suffering drying and wetting cycles, $f_{\mathrm{cn}}$ is the compressive strength of concrete specimen after $N$ times of drying and wetting cycles, and $f_{c 0}$ is the compressive strength of concrete specimen without corrosion.

The relationship between compressive strength of fly ash concrete and number of drying and wetting cycles can be derived from the test results when the sulfate concentrate is $1000 \mathrm{~g} / \mathrm{L}$.
When concrete corroded by $\mathrm{Na}_{2} \mathrm{SO}_{4}$,

$$
K_{c}=-4.234 \times 10^{-3} t^{2}+6.019 \times 10^{-2} t+1 .
$$

When concrete corroded by $\left(\mathrm{NH}_{4}\right)_{2} \mathrm{SO}_{4}$,

$$
K_{c}=-5.406 \times 10^{-3} t^{2}+7.059 \times 10^{-2} t+1,
$$

where $t$ is the number of drying and wetting cycles $(t=0,2,4$, $6,8,10, \ldots)$. In (3) and (4), the maximum relative errors between test value and fitted value are $2.56 \%$ and $2.46 \%$, respectively, under corrosion circumstances of $\mathrm{Na}_{2} \mathrm{SO}_{4}$ and $\left(\mathrm{NH}_{4}\right)_{2} \mathrm{SO}_{4}$. It is reliable to use the above two formulas to predict reduction of strength and service life of concrete.

According to "Standard for Test Methods of Long-Term Performance and Durability of Ordinary Concrete" in the Chinese standard [21] and study of concrete attacked by sulfate [22], the service life of corroded concrete is calculated as follows: the relative compressive strength of concrete falling to $75 \%$ is used as a failure criterion of concrete specimen. $F_{c}$ is adopted as an evaluation parameter, and the calculation formula is as follows:

$$
F_{c}=\frac{K_{c}-0.75}{0.25}
$$

where $F_{c}$ is the failure coefficient of compressive strength. When the relative compressive strength is less than $75 \%$, concrete specimen is regarded as damaged.

Based on (3)-(5) and the designed sulfate concentration, the relative compressive strengths of fly ash concrete corroded by $\mathrm{Na}_{2} \mathrm{SO}_{4}$ and $\left(\mathrm{NH}_{4}\right)_{2} \mathrm{SO}_{4}$ reduce less than $75 \%$ after 18 and 16 circulations of drying and wetting; namely, the compressive strength of fly ash concrete reaches its failure bound.

\section{Conclusions}

(1) The two different corrosion solutions make little difference on the compressive strength of modified concrete after the same drying and wetting cycles. However, the splitting tensile strength suffering from $\mathrm{Na}_{2} \mathrm{SO}_{4}$ is generally higher than that in $\left(\mathrm{NH}_{4}\right)_{2} \mathrm{SO}_{4}$ at initial strengthening stage. At performance deterioration stage, the splitting tensile strength of modified concrete decreased more rapidly in $\mathrm{Na}_{2} \mathrm{SO}_{4}$ to be lower than that in $\left(\mathrm{NH}_{4}\right)_{2} \mathrm{SO}_{4}$.

(2) The addition of admixture significantly improves the ability of sulfate resistance of ordinary concrete. When suffered 10 times of drying and wetting cycle, the compressive strength and splitting tensile strength of modified concrete increase by $28 \%$ and $19 \%$, respectively.

(3) Polypropylene fiber improves the sulfate resistance ability of fly ash concrete to a small degree. Considering construction cost, it is not advised to add polypropylene fiber in fly ash concrete to resist sulfate attack.

(4) Life prediction formula for fly ash concrete corroded by sulfate under the designed sulfate concentration was proposed. Based on the formula, fly ash concrete reaches its compressive strength failure bound and is not suitable for continuous service after 18 and 16 
cycles of drying and wetting corroded by $\mathrm{Na}_{2} \mathrm{SO}_{4}$ and $\left(\mathrm{NH}_{4}\right)_{2} \mathrm{SO}_{4}$, respectively.

\section{Conflicts of Interest}

The authors declare that there are no conflicts of interest in this paper.

\section{Acknowledgments}

The authors would like to acknowledge the financial support received from the National Natural Science Foundation of China (Grant no. 51679221), sponsored by Program for Science \& Technology Innovation Talents in Universities of Henan Province (Grant no. 16HASTIT012).

\section{References}

[1] W. J. Zhang, L. X. Liu, and D. H. Dai, "Experimental study of concrete corroding in brine and fresh water under dry-wet circulation," Journal of Qinghai University (Nature Science), vol. 24, no. 4, pp. 25-29, 2006.

[2] R. Talero, "Performance of metakaolin and Portland cements in ettringite formation as determined by ASTM C 452-68: kinetic and morphological differences," Cement and Concrete Research, vol. 35, no. 7, pp. 1269-1284, 2005.

[3] J. Tulliani, M. Laura, and N. Alfredo, "Sulfate attack of concrete building foundations induced by sewage waters," Cement and Concrete Research, vol. 32, no. 6, pp. 843-849, 2002.

[4] M. Santhanam, M. D. Chole, and J. Olek, "Modeling the effects of solution temperature and concentration during sulfate attack on cement mortars," Cement and Concrete Research, vol. 32, no. 4, pp. 585-592, 2002.

[5] Z. M. Ma, T. J. Zhao, and A. C. Li, "Study on sulfate attack mechanism for concrete in tidal environment," Coastal Engineering, vol. 33, no. 1, pp. 31-36, 2014.

[6] Z. Q. Gu, "Experimental research on strength and fracture properties of hydraulic concrete after three-factor deterioration," Master thesis of Zhengzhou University, Zhengzhou, China, 2015.

[7] Z. X. Yu, J. M. Gao, and L. G. Song, "Damage process of concrete exposed to sulfate attack under drying-wetting cycles and loading," Journal of Southeast University (Natural Science Edition), vol. 42, no. 3, pp. 487-491, 2012.

[8] F. Zheng and G. S. Qin, "Study on the environmental factors influencing the sulfate attack on concrete," Journal of Xuzhou Institute of Technology (Natural Sciences Edition), vol. 25, no. 1 , pp. 21-28, 2010.

[9] A. Neville, "The confused world of sulfate attack on concrete," Cement and Concrete Research, vol. 34, no. 8, pp. 1275-1296, 2004.

[10] GB175-2007, Portland Cement and Ordinary Portland Cement, National Standard of the People's Republic of China, Beijing, China, 2007.

[11] GB/T 1596-2005, Fly Ash Used for Cement and Concrete, National Standard of the People's Republic of China, Beijing, China, 2005.

[12] GB/T 21120-2007, Synthetic Fibers for Cement, Cement Mortar and Concrete, National Standard of the People's Republic of China, Beijing, China, 2007.
[13] JGJ 55-2011, Specification for Mix Proportion Design of Ordinary Concrete, China Architecture \& Building Press, Beijing, China, 2011.

[14] SL 352-2006, Test Code for Hydraulic Concrete, Water Conservancy Industry, Standard of People's Republic of China, Beijing, China, 2006.

[15] Z. Q. Jin, T. J. Zhao, and W. Sun, "Study on damage to concretes attacked by sulfates," Industrial Construction, vol. 38, no. 3, pp. 90-93, 2008.

[16] J. J. Guo, J. H. Han, and Y. Lu, "Mechanical properties of modified concrete exposed to composite corrosive environment," Journal of Building Materials, vol. 16, no. 2, pp. 330334, 2013.

[17] Z. X. Zhang, G. L. Zhang, and F. G. Leng, "Research on concrete stress corrosion in 5\% solution of ammonium sulphate," China Building Materials Science \& Technology, vol. 11, no. 3, pp. 26-30, 2002.

[18] H. L. Wang, Y. S. Dong, and X. Y. Sun, "Damage mechanism of concrete deteriorated by sulfate attack in wet-dry cycle environment," Journal of Chongqing Jianzhu University, vol. 28, no. 4, pp. 118-120, 2006.

[19] J. X. Ye, C. H. Yang, and X. Zhou, "Sulphate attack resistance of the concrete with additives and its assessment," Journal of Zhejiang University (Engineering Science), vol. 46, no. 7, pp. 1255-1261, 2012.

[20] J. H. Han, Y. Wang, and J. J. Guo, "Analysis about erosion of chloride salt on modified concrete," Concrete, vol. 32, no. 8, pp. $48-50,2010$.

[21] GB/T 50082-2009, Standard for Test Methods of Long-Term Performance and Durability of Ordinary Concrete, National Standard of the People's Republic of China, Beijing, China, 2009.

[22] H. X. Qiao, M. R. Zhou, and Y. P. Zhu, "Assessment parameter for concrete performance of anti-sulfate erosion," Fly Ash Comprehensive Utilization, vol. 22, no. 7, pp. 3-6, 2008. 


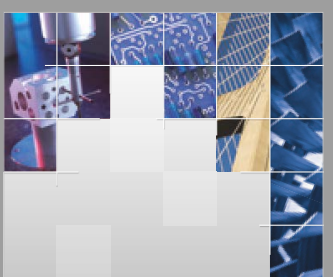

\section{Enfincering}
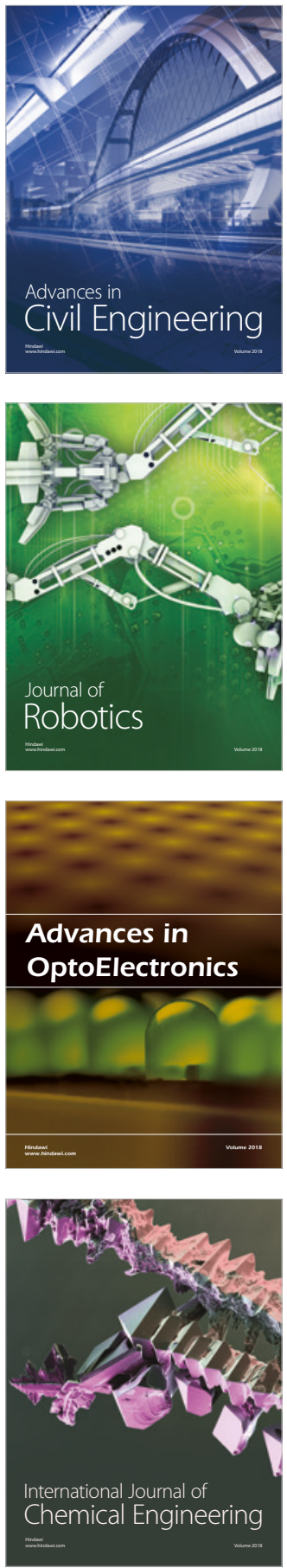

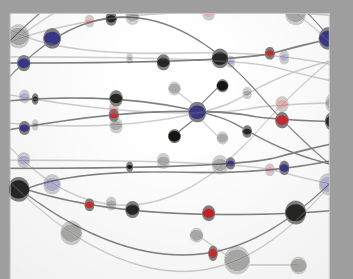

\section{Rotating \\ Machinery}

The Scientific World Journal

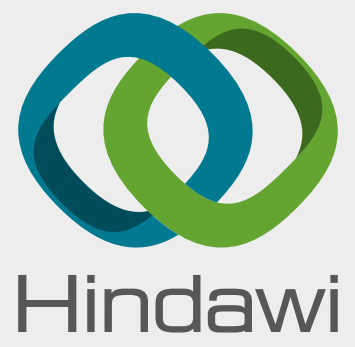

Submit your manuscripts at

www.hindawi.com
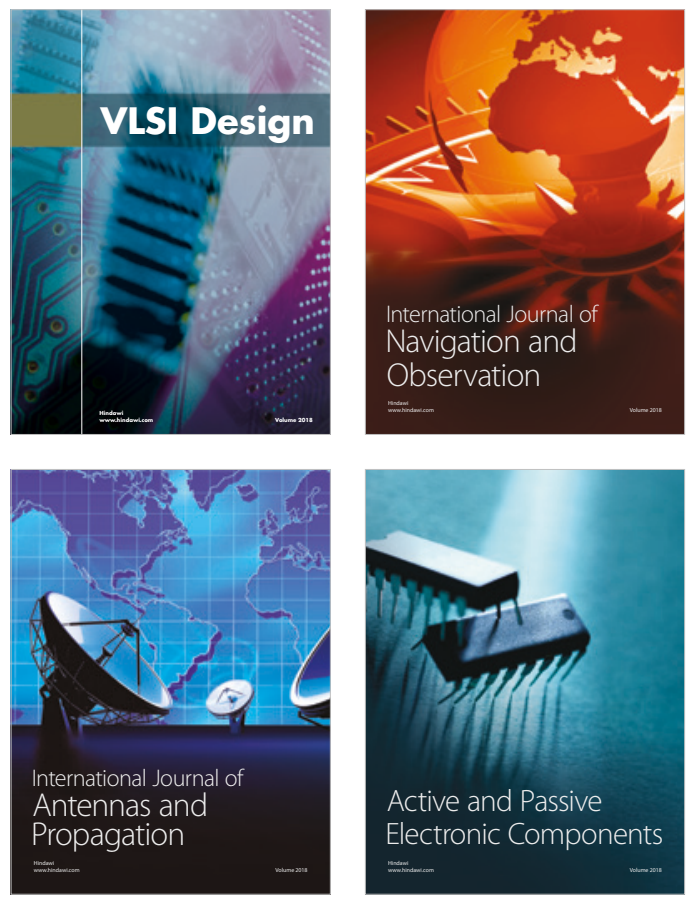
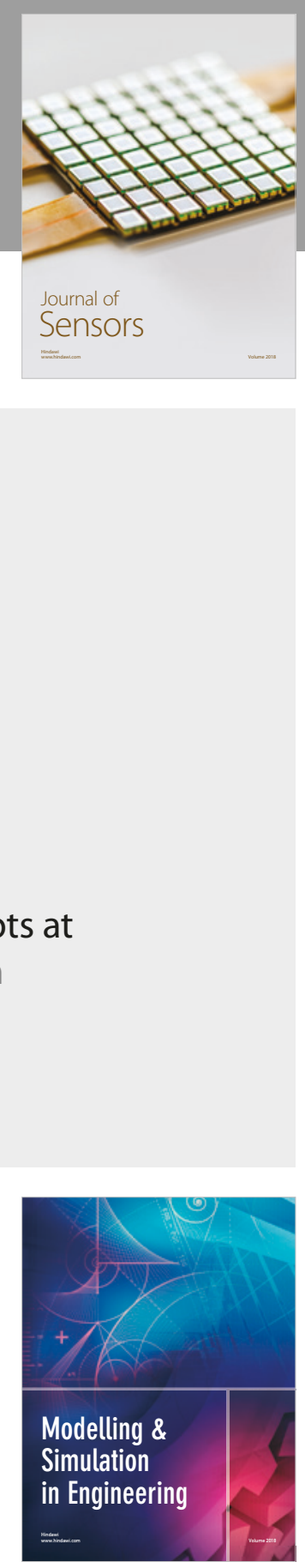

\section{Advances \\ Multimedia}
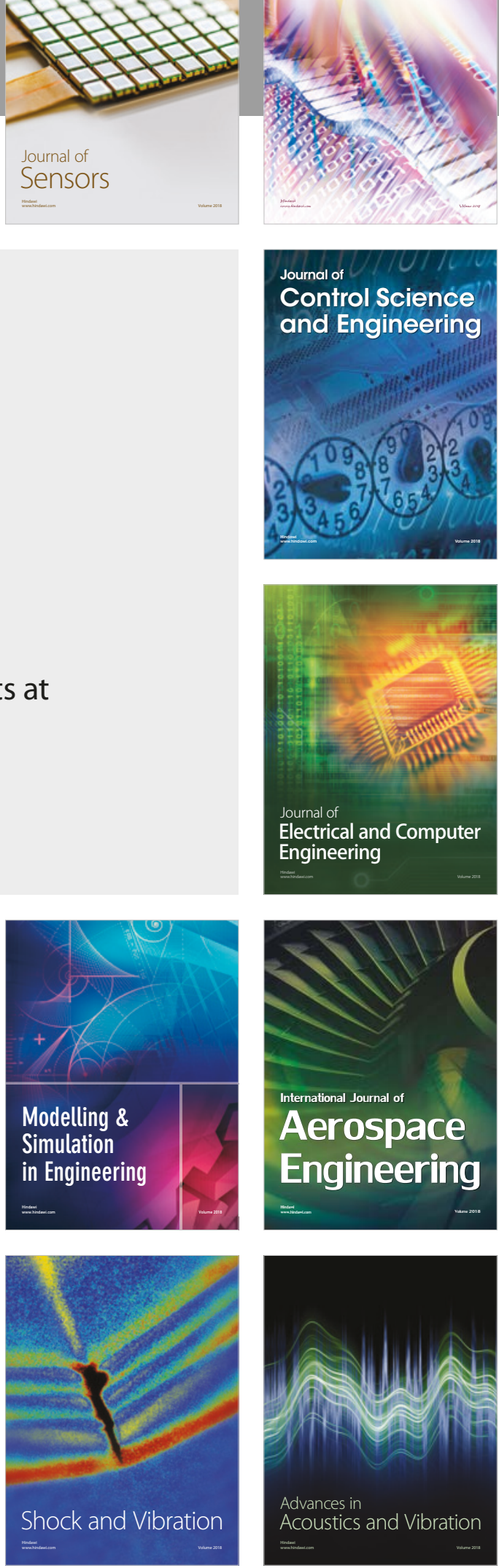